\title{
Forced Exercise in Combination with 1, 25-dihydroxyvitamin D3 Before Induction of 6-hydroxydopamine Protects Dopaminergic Neurons in Rats Model of Parkinson's Disease
}

\author{
Fatemeh Mirfakhrai, ${ }^{1}$ Ziya Fallah Mohammadi, ${ }^{1,}$ and Hossein Fallah Mohammadi ${ }^{2}$ \\ ${ }^{1}$ Department of Exercise Physiology, Faculty of Sport Sciences, University of Mazandaran, Babolsar, Iran \\ ${ }^{2}$ Department of Cell and Molecular Biology, Faculty of Basic Sciences, University of Mazandaran, Babolsar, Iran \\ "Corresponding author: Ziya Fallah Mohammadi, Shahidzolfaghari Blvd., Boalicina Square, Daneshgah Blvd., Pardis University, Babolsar, Iran. E-mail: zia-falm@umz.ac.ir
}

Received 2016 September 14; Revised 2016 November 02; Accepted 2017 April 19.

\begin{abstract}
Background: The protective effect of 1, 25-dihydroxyvitamin D3 (VD3) supplementation along with forced exercise on Parkinson's disease (PD) is subtle.

Objectives: In this experimental study, we investigated the pretreatment effect of 4 weeks of VD3 supplementation and lowintensity treadmill running on dopamine (DA), tyrosine hydroxylase (TH) and insulin-like growth factor 1 (IGF-1) levels in parkinsonian rats.

Methods: In this experimental study, we provided 54 male Wistar rats (12-week old) from Pasteur institute, Iran. One mL/kg BW VD3 was injected every other day. Training encompassed $30 \mathrm{~min} /$ day, 5 days a week over a period of 4 weeks on treadmillat the rate of 15 $\mathrm{m} / \mathrm{min}$. Parkinson's disease (PD) was induced by the stereotaxic surgery injection of 6-hydroxydopamine (6-OHDA) into the striatum of male Wistar rats. For confirming rats with PD, cylinder behavioral rotation test was employed. One way analysis of variance and Tukey post-hoc was utilized for comparing intergroup differences using GraphPad prism (6.07) software.

Results: The level of DA, TH, and IGF-1 in the striatum decreased after nervous toxin injection. VD3 prevented the decrease of the level of these factors significantly, and also combining it with exercise could do so. Four weeks of treadmill running pretreatment could not prevent the level of IGF-1, TH and DA from decreasing. Furthermore, cylinder test results revealed that VD3 alone, and along with exercise prevents the level of these substances from decreasing, and the rotations of PD rats did not show a significant difference compared with the healthy rats which is indicative of neuroprotective effect of this treatment.

Conclusions: VD3 supplementation alongside low-intensity treadmill running had protective effects on behavioral symptoms and molecular changes against the PD-inducing nervous toxin. Therefore, this approach can be used as a protective nonpharmacological tool for brain's health against PD.
\end{abstract}

Keywords: Parkinson's Disease, Dopamine, Tyrosine Hydroxylase, Insulin-Like Growth Factor 1, 1, 25-Dihydroxyvitamin D3, Treadmill Running

\section{Background}

Parkinson's disease (PD) emerges after the destruction of dopamine (DA) secreting cells $[1,2]$. The destruction of dopamine-secreting cells in midbrain disturbs other controlling centers of body movements [3]. PD is identified with four main characteristics: Resting tremor which is known as a low-range involuntary rhythmic movement, bradykinesia (dullness and movement limitation), rigidity (muscle stiffness), and postural instability [4, 5]. Disparate medicines have been offered in order for curing this disease, and among them L-dopa, which has the most usage [6], in this case, encompasses different side effects, and even the long-term consumption of L-dopa is accompanied by pharmaceutical resistance $[7,8]$. Current pharmacological treatments which are preponderantly employed for symptomatic controlling, only offer short-term ben- efits prior to the deterioration of symptoms and pharmacological side effects [9]. As a result, prevention of this disease sounds to be a better approach for controlling and reducing the huge medical expenses [10]. PD patients have less Vitamin D level than their non-PD peers [11]. Cross-sectional studies show a correlation between vitamin D level and the intensity of PD symptoms [12]. Recent studies have demonstrated that vitamin $\mathrm{D}$ can be effective on muscles, immunity, endocrine glands and central nervous system (CNS) [13-16]. This steroid hormone has a significant role in the nervous system including differentiation, calcium regulation, hemostasis, neurotrophins release, brain genes activity and the metabolism of synapses enzymes [17]. It has been explored that vitamin D insufficiency contributes to pathogenesis and PD progress as well [11]. Moreover, this vitamin intervenes in the regu- 
lation of tyrosine hydroxylase (TH) gene expression and, as a result, dopamine biosynthesis [18]. The active form of vitamin D, 1, 25-dihydroxyvitamin D3 (1, 25-(OH)2 D3 ) (VD3) have physiological functions more than that of its conventional role in calcium hemostasis and bone health [19]. It has been reported that exercise exerts neuroprotection through neurogenesis and angiogenesis [20]. Metaanalyses demonstrated that physical exercise improves health-related quality, power, balance and stepping speed in PD patients $[21,22]$. It is suggested that, regular physical exercise decreases the threat of neural impairments such as PD and other neurodegeneration diseases [23]. In addition, exercise accelerates the healing process of substantia nigra-striatum injury, and it also changes the dopaminergic neurotransmission in substantia nigra-striatum system [24]. Although the beneficial effects of exercise in PD treatment are still disputed, it is not cleared yet whether exercise can prevent neurodegeneration. Besides, molecular mechanisms of the possible benefits of exercise in experimental models of PD are not determined [25].It has been postulated that several trophic factors are involved in the processes of the exercise beneficial effects [26]. Neurotrophins like nerve growth factor (NGF), brain-derived neurotrophic factor (BDNF), and insulin-like growth factor (IGF-1) have key roles in life, separation, correlations and neuroplasticity [3]. It has been reported that the deficiency of IGF-1 leads to the cognitive disorder and dementia in elderly $[27,28]$. IGF-1 has multiple impacts on the nervous system and particularly on the structure and synaptic flexibility which is beneficial and necessary for protection and maintenance of cognitive function during senility [29]. Li and colleagues (2015) in meta-analysis of PD patients demonstrated that serum IGF-1 levels in PD patients was significantly higher than healthy control group. The authors support the hypothesis in which the increase in serum IGF-1 level can act as a biomarker for early diagnosis of PD [30]. Ebert and colleagues (2008) suggested that IGF-1 has a dual role in both increasing the hNPC survival after transplantation and trophic effects on degenerating DA neurons in rat model of PD [31]. Treatment by growth hormone (GH) increases the diameters of diencephalic (anterior-posterior, for instance) in the developing brain after birth [32]. Several studies have been conducted about VD3 supplementation and physical exercise separately on the abnormality of brain function [20, 33]. However, there are not any studies in which the prophylactic effect of VD3 supplementation and exercise on the protection of dopamine, TH and IGF-1 levels of rats' striatum would be investigated. So, this study was designed to investigate the pretreatment effect of 4 weeks of VD3 supplementation along with forced treadmill running on the level of dopamine, TH and IGF-1 in parkinsonian rats in- duced by 6-OHDA.

\section{Methods}

In this experimental study, we provided 54 male Wistar rats (12-week old) from Pasteur institute, Iran. After transferring to the laboratory, rats, in order to adapt to the new environment, were maintained during a week in transparent polycarbonate cages at $20-24^{\circ} \mathrm{C}, 45 \%-55 \%$ of humidity, and under a 12:12 hour light/dark cycle.

Rats were randomly divided into 8 groups (6 per group): healthy control, healthy training, Parkinson control, Parkinson training, healthy VD3, Parkinson VD3, and Parkinson VD3 training (combined Parkinson) and healthy VD3 training (combined healthy). During the research period, rats had free access to nutrition and water.

VD3 was prepared from chemical and pharmaceutical corporation KAIMAN(USA). For preparing supplement, 100 $\mu \mathrm{g}$ VD3 was dissolved in $1 \mathrm{~mL}$ of propylene glycol, and then it was solved in saline $9 \%$ (each $\mathrm{mL}$ of solution contains 1 $\mu \mathrm{g}$ of supplement) and finally, it was intraperitoneally injected every other day with the dose of $1 \mathrm{~mL} / \mathrm{kg}$ BW with an insulin syringe [34].

Training groups exercised on the treadmill in a period of 4 weeks, 5 days a week and 30 minutes daily with the rate of $15 \mathrm{~m} / \mathrm{min}$, prior to injecting 6-OHDA.

Parkinson groups went through stereotaxic surgery. Destruction of striatum in rats in order for creating parkinsonian model was carried out using stereotaxic surgery injection of 6-OHDA solution into the brain's striatum.Firstly, in order for anesthetizing the rats, ketamine and Xylazine with the ratio of $5 \mathrm{~mL}$ ketamine, $3 \mathrm{~mL}$ Xylazine were intraperitoneally injected. Then a cannula was designed in 9 mm length ( $7 \mathrm{~mm}$ plastic section and $2 \mathrm{~mm}$ injecting metal section) by 27 gagesyringe and the remaining $1.5 \mathrm{~mm}$ for 30 gage dentistry syringe which was joint to Hamilton syringe. The obtained features for creating the hole and injecting according to the paxinos atlas was as following: 2.5 $\mathrm{mm}$ lateral, $1 \mathrm{mmdownwards}$ from bregma and $4.5 \mathrm{~mm}$ in depth [35]. Rats received $20 \mu \mathrm{g}$ of 6-OHDA ino.4 CC of saline and that this solution was made from a $250 \mu \mathrm{g}$ stock solution which was injected $(0.5 \mu \mathrm{L} / \mathrm{min})$ into the right striatum.

For investigating the effect of 6-OHDA injection, and confirming rats with PD, 21 days after 6-OHDA injection, rotational behavior of apomorphine induction and cylinder test were employed. Cylinder test was carried out in a cylinder with $22 \mathrm{~cm}$ in diameter and $26 \mathrm{~cm}$ height. The total number of complete rotations $\left(360^{\circ}\right)$ in opposite direction of the injured side of striatum following the intraperitoneal injection of $0.5 \mathrm{mg} / \mathrm{kg}$ of apomorphine was counted by the researcher during a period of 30 minutes recorded 
by a video camera. The number of injured side rotations was subtracted from opposite side which is indicative of pure rotation numbers towards opposite side. More rotation is the demonstrator of lesion intensity in terms of dopaminergic cells [36].

After performing behavioral tests, rats were anesthetized by the combination of ketamine and Xylazine, and after opening the skull of rats, striatum tissue was rapidly isolated from other parts of the brain and it was put in liquid nitrogen. After tissue homogenesis in phos-

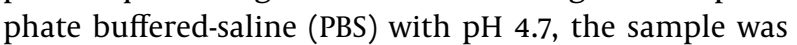
centrifuged at $10000 \mathrm{G}$ for 20 minutes, and concentration levels of DA, TH, and IGF-1 of striatum were measured using commercially available ELISA assays following the instruction supplied by the manufacturer (CUSABIO Corporation kits, China).

Results were presented as means \pm standard deviation (SD). Comparison between experimental and control groups were performed by one-way analysis of variance (ANOVA) which was followed by Tukey's multiple-range post hoc test in order to investigate intergroup differences. Also, $\mathrm{P}<0.05$ was accepted as statistically significant. All statistical analysis and plotting graphics was performed using the GraphPad prism software (version 6.07).

\section{Results}

Evaluation of apomorphine-induced changes in rotational behavior in 21 days after injecting 6-OHDA into the striatum was performed. The number of pure rotation was $106.2 \pm 15.7$ turns/min in the 6-OHDA-injection group. Pretreatment with VD3 prevented the increase of rotational behavior. Furthermore, the combination of VD3 and treadmill running had protective effects against 6-OHDA injection. However, exercise group showed no significant differences compared to Parkinson group (Table 1).

As it is depicted in Figure 1, IGF-1 level in the striatum of Parkinson rats, following the injection of 6-OHDA decreased compared to the healthy control group in which its value reached a significant level $(P=0.0002)$. The results obtained from one way ANOVA revealed that exercise along with supplement injection has resulted in an increase in striatum IGF-1 level of combined Parkinson group compared to the Parkinson group $(\mathrm{P}=0.019)$, but the difference between combined Parkinson group and the healthy control group was not significant $(\mathrm{P}>0.05)$. In addition, IGF-1 levels in combined Parkinson group was higher in comparison with Parkinson training group and Parkinson VD3 group, but its value did not reach a significant level $(\mathrm{P}>$ 0.05). Pretreatment injection of VD3 prevents the decrease of IGF-1 level followed by 6-OHDA injection (Parkinson VD3 group compared to Parkinson group $(\mathrm{P}=0.038)$ ). However, our results was indicative of no significant difference between Parkinson VD3 with healthy control, healthy training and combined Parkinson ( $\mathrm{P}>0.05)$. In other words, using this approach has been effective for protecting IGF-1 levels. It seems that although 6-OHDA had a noticeable impact on the IGF-1 decrease, exercise and VD3injection was able to prevent this neurotrophic factor from decreasing. Figure 1. Effects of 4 Weeks of VD3 Along with Treadmill Running Pretreatment on
Striatum IGF-1 Before 6-OHDA Injection

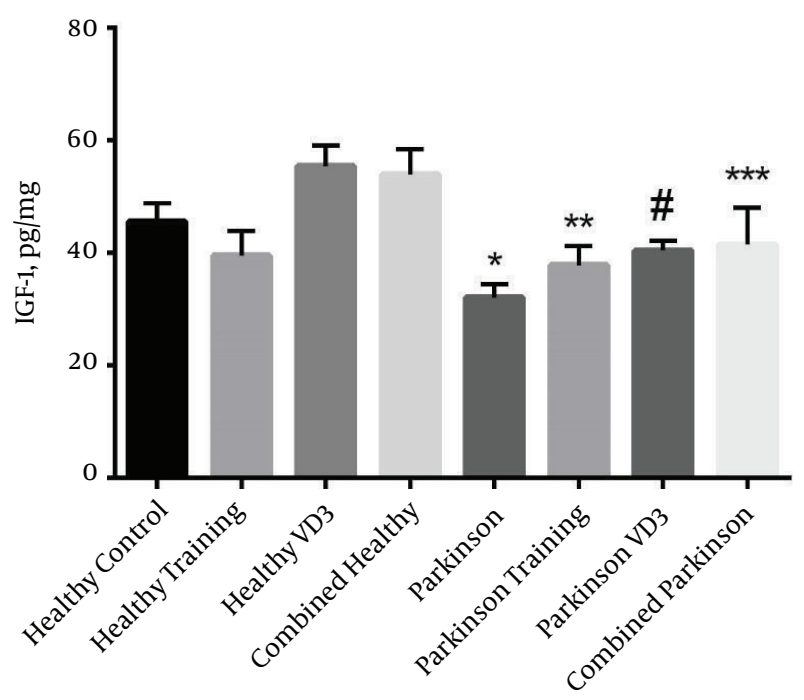

${ }^{*} \mathrm{P}<0.05$ Parkinson versus healthy control; ${ }^{* *} \mathrm{P}<0.05$ parkinson training versus healthy training; ${ }^{* * *} \mathrm{P}<0.05$ combined Parkinson versus Parkinson; \#P $<0.05$ parkinson VD3 versus Parkinson.

The results of one way ANOVA demonstrated that exercise in combination with VD3 have had a significant effect on DA in thestriatum of parkinsonian rats in which the values of DA in combined Parkinson group was higher than Parkinson group $(\mathrm{P}=0.0001)$. But the difference between combined Parkinson group and healthy control group was not significant $(\mathrm{P}>0.05$ ) (Figure 2). Moreover, DA values in combined Parkinson group was higher than Parkinson training group $(\mathrm{P}=0.0001)$, but it did not show a significant difference compared with the Parkinson VD3 group ( $P$ $>0.05$ ).

The results show that exercise with VD3 have a significant effect on $\mathrm{TH}$ level in striatum of parkinsonian rats in which TH levels was higher than Parkinson group ( $P$ $=0.0001$ ). However, the difference between combined Parkinson group and healthy control group was not significant $(\mathrm{P}>0.05)$. Furthermore, TH values in combined Parkinson group had a significant higher level compared to the Parkinson training group $(\mathrm{P}=0.0001)$ although it did not have a significant difference compared with the 
Table 1. Effect of 4 Weeks Treadmill Running and VD3 on Number of Rotations in Cylinder Test Followed by Apomorphine Injection ${ }^{\mathrm{a}}$

\begin{tabular}{lccccccc}
\hline Groups & Parkinson & $\begin{array}{c}\text { Parkinson } \\
\text { Training }\end{array}$ & $\begin{array}{c}\text { Healthy } \\
\text { Training }\end{array}$ & $\begin{array}{c}\text { Healthy } \\
\text { Control }\end{array}$ & $\begin{array}{c}\text { Combined } \\
\text { Parkinson }\end{array}$ & $\begin{array}{c}\text { Combined } \\
\text { Healthy }\end{array}$ & $\begin{array}{c}\text { Healthy VD3 } \\
\text { Parkinson VD3 }\end{array}$ \\
\hline Mean \pm SD & $106.2 \pm 15.7^{\mathrm{b}}$ & $93.2 \pm 18.2^{\mathrm{c}}$ & $5.8 \pm 4.95$ & $5.5 \pm 6.7$ & $21.4 \pm 19.0$ & $6 \pm 6.24$ & $1.17 \pm 2$ \\
\hline
\end{tabular}

${ }^{\mathrm{a}}$ The values were analyzed by one-way ANOVA and Tukey comparison test.

${ }^{\mathrm{b}} \mathrm{P}<0.001$ Parkinson group versus healthy control group.

${ }^{\mathrm{c}} \mathrm{P}<0.001$ Parkinson training group versus healthy training group

Figure 2. Effects of 4 Weeks of VD3 Along with Treadmill Running Pretreatment on Striatum DA Before 6-OHDA Injection

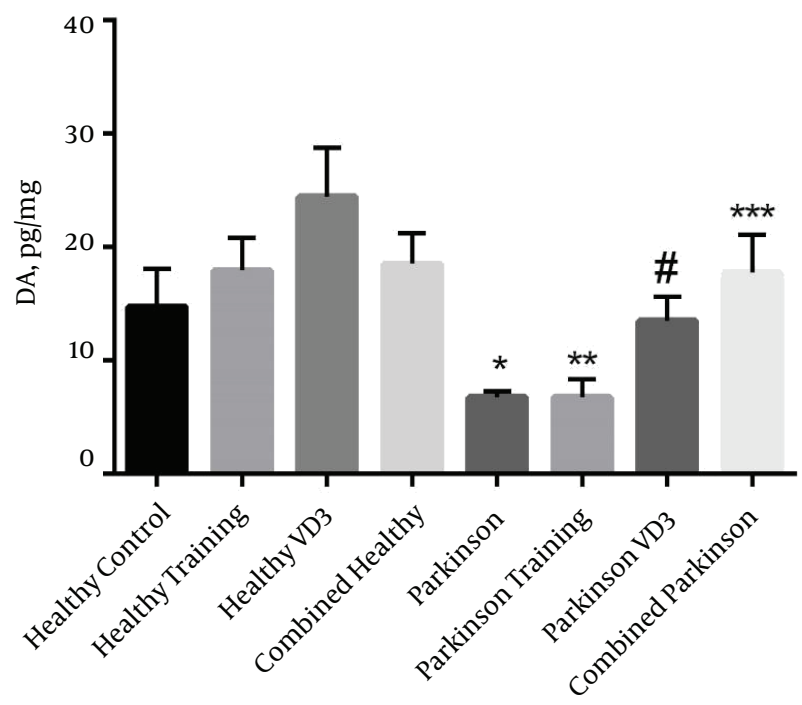

${ }^{*} \mathrm{P}<0.05$ Parkinson versus healthy control. ${ }^{* *} \mathrm{P}<0.05$ parkinson training versus healthy training. ${ }^{* * *} \mathrm{P}<0.05$ combined parkinson versus parkinson. $\# \mathrm{P}<0.05$ parkinson VD3 versus parkinson.

Parkinson VD3 group ( $\mathrm{P}>0.05)$ (Figure 3).

\section{Discussion}

This study indicates a neural protective effect of treadmill running alongside VD3 supplementation over a period of 4 weeks. The study was conducted before receiving nervous toxin 6-OHDA on the level of IGF-1, DA and TH in the striatum of rats. It has bees postulated that their effects was more than the impacts of them separately. In fact, one of the objectives of this research was to investigate the reinforcing effect of exercise and VD3 supplementation at the same time. In other words, this question was raised whether an exercise program and VD3 supplementation together can increase the neuroprotective effect in parkinsonian rats. It is probable that owing to the impact of exercise and VD3 supplementation on IGF-1, the cooperation of these two variable results in IGF-1preservation, DA
Figure 3. Effects of 4 Weeks of VD3 Along with Treadmill Running Pretreatment on Striatum TH Before 6-OHDA Injection

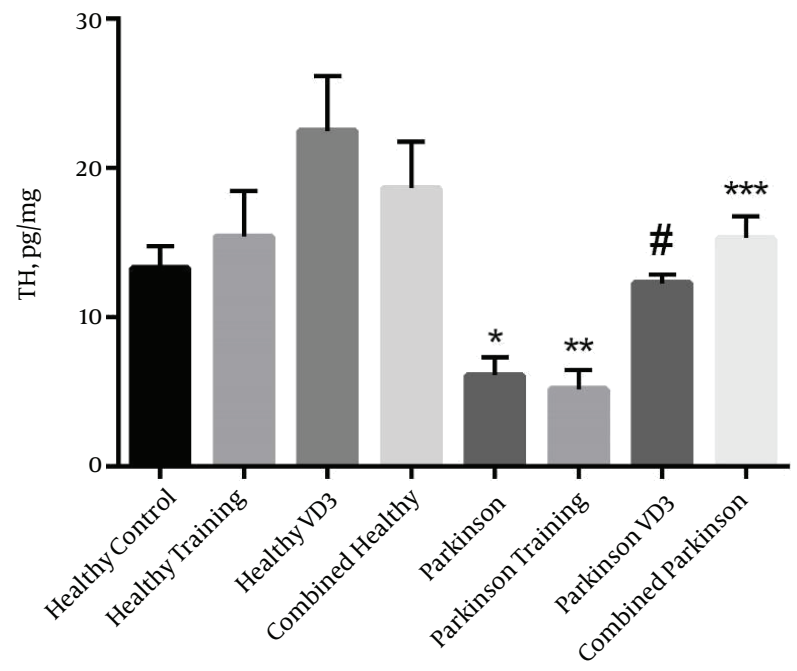

${ }^{*} \mathrm{P}<0.05$ Parkinson versus healthy control. ${ }^{* *} \mathrm{P}<0.05$ parkinson training versus healthy training. ${ }^{* * *} \mathrm{P}<0.05$ combined parkinson versus parkinson. \#P $<0.05$ parkinson VD3 versus Parkinson.

and $\mathrm{TH}$ resources maintenance, and consequently protection of striatum dopaminergic cells. On the other hand, possibly, simultaneous deployment of exercise and supplementation culminates in an increase in DA secretion from the remaining cells. Also, it is probable that this increase is the result of DA production in other parts of the brain and their return to striatum with backwards mechanism [37]. Offen and colleagues (2001) suggest that IGF-1 have neuroprotective effect against DA-induced toxicity, and it may have a potential role in PD treatment. This effect of IGF-1 had a correlation with increased expression of Bcl-2 [27]. Ayadi and colleagues (2016) investigated the protective effect of IGF-1 on DA neurons against oxidative stress. They find out that this protein can protect the nigrostriatal pathway in progressive PD model and this protection is preceded by activation of key pro-survival signaling cascades [38].

VD3, with regard to having active receptors in the 
brain, leads to the decrease of inflammations derived from neurological diseases like PD [39]. Some correlations between vitamin D levels and diseases such as cancer, arthritis, diabetes, and muscle fibers atrophy have been observed $[40,41]$. In order to investigate the effect of exercise on the improvement of lost nervous dopaminergic cells in parkinsonian model rats, Choe and colleagues (2012) showed that exercise may have a protective effect on neurons against the nervous toxin-derived death. The results of mentioned study demonstrated that exercise deactivates glycogen synthase kinase $3 \beta$ (GSK3ß) through phosphorylation that can be responsible for protective effect of exercise on 6-OHDA-derived cell death [4]. 6-OHDA exerted its neural destructive effects by increasing oxidative stress. Regarding the presented articles, it seems that the results acquired from combining exercise and VD3 supplementation are due to the anti-inflammatory effect of these two independent variables. It is probable that the antiinflammatory effect of exercise and VD3 is in the form of both indirect (neurotrophic factors mediation), and direct (increase in dopamine production by dopaminergic cells of other parts of the brain and undamaged part of the striatum). Although it has been demonstrated that exercise alone can prevent the inflammation [42-44], these circumstances decrease by increasing intensity and exercisederived stress, and it causes more tissue injuries including the brain [45]. VD3 can stimulate the release of reactive oxygen species (ROS) inhibitory factors such as lipoxygenase [33, 46-48]. Furthermore, VD3 can lead to thereduction of ROS in the liver of rats through its capability in reducing lipid peroxidation [49]. It seems that the antiinflammatory effects of combining these 2 factors may reduce the nervous and muscle injury. Probably, combining exercise and VD3 supplementation have indirect and direct effects sothat VD3 causes the exercise and 6-OHDA-derived injuries to decrease. On the other hand, exercise can indirectly increase the production of neurotrophic factors, and prevents this injury $[26,50,51]$. The other possibility that can be mentioned for the combined effect is referred to the exercise-derived hormone response. It has been revealed that an increase in parathyroid hormone is secreted by parathyroid glands in response to the VD3 reduction in order for increasing intestine absorption and activating it. So it seems that exercise can increase parathyroid hormone $[52,53]$. This exercise-derived increase can be occurred in order to compensate for VD3 reduction. In other words, it appears that exercise leads to the attenuation of mentioned physiological functions in the brain by its negative impact on VD3 level. Possibly, VD3 supplementation and exercise can separately prevent the exercise-derived reduction of VD3, and so do that for physiological functions reduction of VD3 in the brain.
The result of this research showed that the injection of VD3 culminates in an increase in the resistance of striatum DA cells against the oxidation-derived damage created by 6-OHDA. On the other hand, exercise and VD3 supplementation can increase the level of DA, TH and IGF-1 in the striatum of parkinsonian rats. However, exercise alone did not have significant effects on the levels of these variables, and also on the cylinder rotation test results.

\section{Acknowledgments}

This article was written according to the Master's thesis numbered 1185794 in university of Mazandaran. The authors are grateful of University of Mazandaran for supporting this research.

\section{Footnotes}

Authors' Contribution: Study concept and design: Ziya Fallah Mohammadi and Fatemeh Mirfakhrai; acquisition of data: Fatemeh Mirfakhrai; analysis and interpretation of data: Zyia Fallah Mohammadi and Hossein Fallah Mohammadi; drafting of the manuscript: Ziya Fallah Mohammadi, Hossein Fallah Mohammadi and Fatemeh Mirfakhrai; critical revision of the manuscript for important intellectual content: Ziya Fallah Mohammadi; statistical analysis: Hossein Fallah Mohammadi; study supervision: Ziya Fallah Mohammadi

Financial Disclosure: The authors have no conflict of interest to report.

Funding/Support: The study has been conducted with personal expenses of the authors and the authors are thankful of Mazandaran university research deputy for supporting this research.

\section{References}

1. Cheng HC, Ulane CM, Burke RE. Clinical progression in Parkinson disease and the neurobiology of axons. Ann Neurol. 2010;67(6):715-25. doi: 10.1002/ana.21995. [PubMed: 20517933].

2. Wu SY, Wang TF, Yu L, Jen CJ, Chuang JI, Wu FS, et al. Running exercise protects the substantia nigra dopaminergic neurons against inflammation-induced degeneration via the activation of BDNF signaling pathway. Brain Behav Immun. 2011;25(1):135-46. doi: 10.1016/j.bbi.2010.09.006. [PubMed: 20851176].

3. Kim H, Heo HI, Kim DH, Ko IG, Lee SS, Kim SE, et al. Treadmill exercise and methylphenidate ameliorate symptoms of attention deficit/hyperactivity disorder through enhancing dopamine synthesis and brain-derived neurotrophic factor expression in spontaneous hypertensive rats. Neurosci Lett. 2011;504(1):35-9. doi: 10.1016/j.neulet.2011.08.052. [PubMed: 21907264]. 
4. Choe MA, Koo BS, An GJ, Jeon S. Effects of Treadmill Exercise on the Recovery of Dopaminergic Neuron Loss and Muscle Atrophy in the 6OHDA Lesioned Parkinson's Disease Rat Model. Korean J Physiol Pharmacol. 2012;16(5):305-12. doi: 10.4196/kjpp.2012.16.5.305. [PubMed: 23129977].

5. Goes AT, Souza LC, Filho CB, Del Fabbro L, De Gomes MG, Boeira SP, et al. Neuroprotective effects of swimming training in a mouse model of Parkinson's disease induced by 6-hydroxydopamine. Neuroscience. 2014;256:61-71. doi: 10.1016/j.neuroscience.2013.09.042. [PubMed: 24090962].

6. Joyce JN, Ryoo HL, Beach TB, Caviness JN, Stacy M, Gurevich EV. Loss of response to levodopa in Parkinson's disease and co-occurrence with dementia: role of D 3 and not D 2 receptors. Brain Res Bull. 2002;955:138-52.

7. Barbeau A. L-dopa therapy in Parkinson's disease: a critical review of nine years' experience. Can Med Assoc J. 1969;101:59-68.

8. Huot P, Johnston TH, Koprich JB, Fox SH, Brotchie JM. The pharmacology of L-DOPA-induced dyskinesia in Parkinson's disease. Pharmacol Rev. 2013;65(1):171-222. doi: 10.1124/pr.111.005678. [PubMed: 23319549].

9. Marino MJ, Williams DJ, O'Brien JA, Valenti O, McDonald TP, Clements MK, et al. Allosteric modulation of group III metabotropic glutamate receptor 4: a potential approach to Parkinson's disease treatment. Proc Natl Acad Sci U S A. 2003;100(23):13668-73. doi: 10.1073/pnas.1835724100. [PubMed: 14593202].

10. Farag I, Sherrington C, Hayes A, Canning CG, Lord SR, Close JC, et al. Economic evaluation of a falls prevention exercise program among people With Parkinson's disease. Mov Disord. 2016;31(1):53-61. doi: 10.1002/mds.26420. [PubMed: 26395438].

11. Knekt P, Kilkkinen A, Rissanen H, Marniemi J, Saaksjarvi K, Heliovaara M. Serum vitamin D and the risk of Parkinson disease. Arch Neurol. 2010;67(7):808-11. doi: 10.1001/archneurol.2010.120. [PubMed: 20625085].

12. Cui X, Pelekanos M, Liu PY, Burne TH, McGrath JJ, Eyles DW. The vitamin $\mathrm{D}$ receptor in dopamine neurons; its presence in human substantia nigra and its ontogenesis in rat midbrain. Neuroscience. 2013;236:77-87. doi: 10.1016/j.neuroscience.2013.01.035. [PubMed: 23352937].

13. Evatt ML, Delong MR, Khazai N, Rosen A, Triche S, Tangpricha V. Prevalence of vitamin d insufficiency in patients with Parkinson disease and Alzheimer disease. Arch Neurol. 2008;65(10):1348-52. doi: 10.1001/archneur.65.10.1348. [PubMed: 18852350].

14. Kulie T, Groff A, Redmer J, Hounshell J, Schrager S. Vitamin D: an evidence-based review. JAm Board Fam Med. 2009;22(6):698-706. doi: 10.3122/jabfm.2009.06.090037. [PubMed:19897699].

15. Pludowski P, Holick MF, Pilz S, Wagner CL, Hollis BW, Grant WB, et al. Vitamin D effects on musculoskeletal health, immunity, autoimmunity, cardiovascular disease, cancer, fertility, pregnancy, dementia and mortality-a review of recent evidence. Autoimmun Rev. 2013;12(10):976-89. doi: 10.1016/j.autrev.2013.02.004. [PubMed: 23542507].

16. Stockton KA, Mengersen K, Paratz JD, Kandiah D, Bennell KL. Effect of vitamin D supplementation on muscle strength: a systematic review and meta-analysis. Osteoporos Int. 2011;22(3):859-71. doi: 10.1007/s00198-010-1407-y. [PubMed: 20924748].

17. Kalueff AV, Minasyan A, Tuohimaa P. Anticonvulsant effects of 1,25dihydroxyvitamin D in chemically induced seizures in mice. Brain Res Bull. 2005;67(1-2):156-60. doi: 10.1016/j.brainresbull.2005.06.022. [PubMed: 16140175].

18. Chitsaz Keivan Basiri A, Izadi Boroujeni M, Tanhaei AP, Rahimi M, Rokhsareh Meamar MM. 25-Hydroxyvitamin D and severity of parkinson's disease. Int J Endocrinol. 2013:4.

19. Jones G, Strugnell SA, DeLuca HF. Current understanding of the molecular actions of vitamin D. Physiol Rev. 1998;78(4):1193-231. [PubMed: 9790574].

20. da Silva PG, Domingues DD, de Carvalho LA, Allodi S, Correa CL. Neurotrophic factors in Parkinson's disease are regulated by ex- ercise: Evidence-based practice. J Neurol Sci. 2016;363:5-15. doi 10.1016/j.jns.2016.02.017. [PubMed: 27000212].

21. Goodwin VA, Richards SH, Taylor RS, Taylor AH, Campbell JL. The effectiveness of exercise interventions for people with Parkinson's disease: a systematic review and meta-analysis. Mov Disord. 2008;23(5):631-40 doi: 10.1002/mds.21922. [PubMed: 18181210].

22. Klamroth S, Steib S, Devan S, Pfeifer K. Effects of Exercise Therapy on Postural Instability in Parkinson Disease: A Meta-analysis. J Neurol Phys Ther. 2016;40(1):3-14. doi: 10.1097/NPT.0000000000000117. [PubMed: 26655098].

23. Smith $\mathrm{AD}$, Zigmond MJ. Can the brain be protected through exercise? Lessons from an animal model of parkinsonism. Exp Neurol. 2003;184(1):31-9. [PubMed: 14637076].

24. Yoon MC, Shin MS, Kim TS, Kim BK, Ko IG, Sung YH, et al. Treadmill exercise suppresses nigrostriatal dopaminergic neuronal loss in 6-hydroxydopamine-induced Parkinson's rats. Neurosci Lett. 2007;423(1):12-7. doi: 10.1016/j.neulet.2007.06.031. [PubMed: $17644250]$.

25. Falvo MJ, Schilling BK, Earhart GM. Parkinson's disease and resistive exercise: rationale, review, and recommendations. Mov Disord 2008;23(1):1-11. doi: 10.1002/mds.21690. [PubMed: 17894327].

26. Zigmond MJ, Smeyne RJ. Exercise: is it a neuroprotective and if so, how does it work?. Parkinsonism Relat Disord. 2014;20 Suppl 1:S123-7. doi: 10.1016/S1353-8020(13)70030-0. [PubMed: 24262162].

27. Offen D, Shtaif B, Hadad D, Weizman A, Melamed E, Gil-Ad I. Protective effect of insulin-like-growth-factor-1 against dopamine-induced neurotoxicity in human and rodent neuronal cultures: possible implications for Parkinson's disease. Neurosci Lett. 2001;316(3):129-32. [PubMed: 11744219].

28. Doi T, Shimada H, Makizako H, Tsutsumimoto K, Hotta R, Nakakubo S Insulin-like growth factor-1 related to disability among older adults.J Gerontol Ser A Biol Sci Med Sci. 2015.

29. Gillespie CM, Merkel AL, Martin AA. Effects of insulin-like growth factor-I and LR3IGF-I on regional blood flow in normal rats. $J$ Endocrinol. 1997;155(2):351-8. [PubMed: 9415069].

30. Li DH, He YC, Quinn TJ, Liu J. Serum Insulin-Like Growth Factor-1 in Patients with De Novo, Drug Naive Parkinson's Disease: A Meta-Analysis PLoS One. 2015;10(12):0144755. doi: 10.1371/journal.pone.0144755. [PubMed: 26657015].

31. Ebert AD, Beres AJ, Barber AE, Svendsen CN. Human neural progenitor cells over-expressing IGF-1 protect dopamine neurons and restore function in a rat model of Parkinson's disease. Exp Neurol. 2008;209(1):213-23. doi: 10.1016/j.expneurol.2007.09.022. [PubMed: 18061591].

32. Morisawa K, Sugisaki T, Kanamatsu T, Aoki T, Noguchi T. Factors contributing to cerebral hypomyelination in the growth hormonedeficient little mouse. Neurochem Res. 1989;14(2):173-7. [PubMed: 2542821].

33. Eyles DW, Burne TH, McGrath JJ. Vitamin D, effects on brain development, adult brain function and the links between low levels of vitamin D and neuropsychiatric disease. Front Neuroendocrinol. 2013;34(1):47-64. doi: 10.1016/j.yfrne.2012.07.001. [PubMed: 22796576].

34. Smith MP, Fletcher-Turner A, Yurek DM, Cass WA. Calcitriol protection against dopamine loss induced by intracerebroventricular administration of 6-hydroxydopamine. Neurochem Res. 2006;31(4):533-9. doi: 10.1007/s11064-006-9048-4. [PubMed: 16758362].

35. Carlsson T, Schindler FR, Hollerhage M, Depboylu C, Arias-Carrion $\mathrm{O}$, Schnurrbusch $\mathrm{S}$, et al. Systemic administration of neuregulin1beta1 protects dopaminergic neurons in a mouse model of Parkinson's disease. J Neurochem. 2011;117(6):1066-74. doi: 10.1111/j.14714159.2011.07284.x. [PubMed: 21517849].

36. Landers MR, Kinney JW, Van Breukelen F. Forced exercise before or after induction of 6-OHDA-mediated nigrostriatal insult does not mitigate behavioral asymmetry in a hemiparkinsonian rat model.. Brain Res Bull. 2014;1543:263-70. 
37. Mabandla M, Kellaway L, St Clair Gibson A, Russell VA. Voluntary running provides neuroprotection in rats after 6-hydroxydopamine injection into the medial forebrain bundle. Metab Brain Dis. 2004;19(12):43-50. [PubMed: 15214505].

38. Ayadi A, Zigmond MJ, Smith AD. IGF-1 protects dopamine neurons against oxidative stress: association with changes in phosphokinases. Exp Brain Res. 2016.

39. Smolders J, Moen SM, Damoiseaux J, Huitinga I, Holmoy T. Vitamin $\mathrm{D}$ in the healthy and inflamed central nervous system: access and function. J Neurol Sci. 2011;311(1-2):37-43. doi: 10.1016/j.jns.2011.07.033. [PubMed: 21862439].

40. Choi M, Park H, Cho S, Lee M. Vitamin D3 supplementation modulates inflammatory responses from the muscle damage induced by high-intensity exercise in SD rats. Cytokine. 2013;63(1):27-35. doi: 10.1016/j.cyto.2013.03.018. [PubMed: 23669253].

41. Holick MF. Vitamin D: importance in the prevention of cancers, type 1 diabetes, heart disease, and osteoporosis. Am J Clin Nutr 2004;79(3):362-71. [PubMed: 14985208].

42. Cotman CW, Berchtold NC, Christie LA. Exercise builds brain health key roles of growth factor cascades and inflammation. Trends Neurosci. 2007;30(9):464-72. doi: 10.1016/j.tins.2007.06.011. [PubMed: 17765329].

43. Woods JA, Wilund KR, Martin SA, Kistler BM. Exercise, inflammation and aging. Aging Dis. 2012;3(1):130-40. [PubMed: 22500274].

44. Sung YH, Kim SC, Hong HP, Park CY, Shin MS, Kim CJ, et al. Treadmill exercise ameliorates dopaminergic neuronal loss through suppressing microglial activation in Parkinson's disease mice. Life Sci. 2012;91(2526):1309-16. doi: 10.1016/j.lfs.2012.10.003. [PubMed: 23069581].

45. Morillas-Ruiz JM, Villegas Garcia JA, Lopez FJ, Vidal-Guevara ML, Zafrilla P. Effects of polyphenolic antioxidants on exerciseinduced oxidative stress. Clin Nutr. 2006;25(3):444-53. doi: 10.1016/j.clnu.2005.11.007. [PubMed:16426710].
46. Harms LR, Burne TH, Eyles DW, McGrath JJ. Vitamin D and the brain. Best Pract Res Clin Endocrinol Metab. 2011;25(4):657-69. doi: 10.1016/j.beem.2011.05.009. [PubMed: 21872806].

47. Shinpo K, Kikuchi S, Sasaki H, Moriwaka F, Tashiro K. Effect of 1,25dihydroxyvitamin $\mathrm{D}(3)$ on cultured mesencephalic dopaminergic neurons to the combined toxicity caused by L-buthionine sulfoximine and 1-methyl-4-phenylpyridine. J Neurosci Res. 2000;62(3):37482. doi: 10.1002/1097-4547(20001101)62:3<374::AID-JNR7>3.0.CO;2-7. [PubMed: 11054806].

48. Newmark HL, Newmark J. Vitamin D and Parkinson's disease-a hypothesis. Mov Disord. 2007;22(4):461-8. doi: 10.1002/mds.21317. [PubMed: 17230473]

49. Lev N, Melamed E, Offen D. Apoptosis and Parkinson's disease. Prog Neuropsychopharmacol Biol Psychiatry. 2003;27(2):245-50. doi: 10.1016/S0278-5846(03)00019-8. [PubMed:12657363].

50. Mabandla MV, Russell VA. Voluntary exercise reduces the neurotoxic effects of 6-hydroxydopamine in maternally separated rats. Behav Brain Res. 2010;211(1):16-22. doi: 10.1016/j.bbr.2010.02.045. [PubMed: 20206210].

51. Speelman AD, van de Warrenburg BP, van Nimwegen M, Petzinger GM, Munneke M, Bloem BR. How might physical activity benefit patients with Parkinson disease?. Nat Rev Neurol. 2011;7(9):528-34. doi: 10.1038/nrneurol.2011.107. [PubMed: 21750523].

52. Scott JP, Sale C, Greeves JP, Casey A, Dutton J, Fraser WD. Treadmill running reduces parathyroid hormone concentrations during recovery compared with a nonexercising control group.JClin Endocrinol Metab. 2014;99(5):1774-82. doi: 10.1210/jc.2013-3027. [PubMed: 24476072].

53. Tosun A, Bolukbasi N, Cingi E, Beyazova M, Unlu M. Acute effects of a single session of aerobic exercise with or without weightlifting on bone turnover in healthy young women. Mod Rheumatol. 2006;16(5):300-4. doi: 10.1007/s10165-006-0503-5. [PubMed:17039311]. 